\title{
Penerapan Metode Pewarnaan Graf Untuk Penjadwalan Mata Kuliah
}

\author{
Amelia Yusnita ${ }^{1}$, Hanifah Ekawati ${ }^{2}$, Nila Ratna Sari ${ }^{3}$ \\ ${ }^{1}$ Sistem Informasi, STMIK Widya Cipta Dharma, Samarinda, Indonesia \\ ${ }^{2}$ Manajemen Informatika, STMIK Widya Cipta Dharma, Samarinda, Indonesia \\ ${ }^{3}$ Teknik Informatika, STMIK Widya Cipta Dharma, Samarinda, Indonesia \\ Email: ${ }^{1}$ amelia@ wicida.ac.id, ${ }^{2}$ hanifahekawati.mus88@gmail.com, ${ }^{3}$ nila.ratna47@gmail.com
}

\begin{abstract}
Abstrak
Penjadwalan matakuliah merupakan agenda yang rutin setiap semester dikerjakan oleh program studi, dalam proses pembuatannya sering mengalami kesulitan misalnya sering terjadi bentrok jadwal mata kuliah, dosen dan waktu yang lain dalam satu periode jadwal perkuliahan. Metode pewarnaan graf yang digunakan adalah algoritma pewarnaan barisan sederhana pada sisi. Algoritma ini dapat digunakan dalam pembentukan jadwal agar tidak terjadinya tumpang tindih antara mata kuliah, dosen, ruangan dan waktu. Alat bantu perancangan sistem yang digunakan adalah flowchrt. Hasil dari penelitian ini adalah berupa aplikasi yang dibuat secara otomatis tanpa ada bentrok jadwal. Pengguna dapat memasukkan data awal penjadwalan sesuai dengan kebutuhan kemudian aplikasi akan menyusul penjadwalan dengan menggunakan algoritma pewarnaan barisan sederhana pada sisi, dan hasil outputnya akan menampilkan hasil penjadwalan tersebut. pengujian menggunakan black box, pengujian ini akan menguji secara detail dari tombol tambah dan tombol proses, hasil yang diharapkan adalah keberhasilan.
\end{abstract}

Kata Kunci: Penjadwalan, Metode Pewarnaan Graf

\section{Abstract}

Scheduling courses is a routine agenda every semester carried out by the study program, in the manufacturing process it often experiences difficulties such as frequent clashes between courses, lecturers and other times in one period of the lecture schedule. The graph coloring method used is a simple row coloring algorithm on the side. This algorithm can be used in scheduling so that there is no overlap between courses, lecturers, room and time. The system design tool used is a flowchart. The results of this study are in the form of applications that are made automatically without any conflicting schedules. Users can enter the initial scheduling data according to their needs, then the application will follow scheduling using a simple line coloring algorithm on the side, and the output results will display the scheduling results. testing using black box, this test will test in detail the plus button and process button, the expected result is a success

Keywords: Scheduling, Graph Coloring Method

\section{PENDAHULUAN}

Pemanfaatan sumber daya manusia dalam sebuah aplikasi yang tepat dapat mempermudah pengguna untuk menyelesaikan pekerjaan dalam skala kecil atau besar, pemanfaatan yang tepat akan sangat membantu dalam kelancaran atau kecepatan penyelesaian berbagai macam pekerjaan.

Penjadwalan merupakan kegiatan yang harus dimiliki oleh setiap orang, kegiatan rutin yang tersusun dengan rapi dapat membantu dalam aktivitas sehari-hari. Dalam sebuah Instansi atau lembaga khususnya misalnya STMIK Widya Cipta Dharma, memiliki agenda-agenda yang harus diselesaikan dengan cepat dan tepat, salah satu agendanya adalah jadwal perkuliahan yang dikerjakan oleh program studi. Masalah yang harus dihindari dalam pembuatan jadwal perkuliahan salah satunya adalah pada waktu dan ruangan yang sama terdapat mata kuliah lebih dari satu. Untuk menghindari terjadinya tumpang tindih antara mata kuliah, dosen, ruangan dan waktu. Salah satu metode yang dapat digunakan untuk menyelesaikan permasalahan tersebut adalah dengan menggunakan metode pewarnaan graf dengan algoritma pewarnaan barisan-sederhana pada sisi.

Berdasarkan latar belakan masalah tersebut. Aplikasi yang dibuat dengan penerapan metode pewarnaan graf untuk penjadwalan mata kuliah, diharapkan dapat mempermudah program studi dalam menyusun jadwal perkuliahan tiap semesternya.

\section{TEORITIS}

Metode pengumpulan data yang digunakan untuk mengolah informasi dibagi menjadi 2 (dua) yaitu :

\subsection{Studi Lapangan}

Metode yang digunakan dalam studi lapangan adalah:

a. Wawancara, pengumpulan data dengan melakukan tanya jawab sepihak yang dilakukan secara sistematik dan berlandaskan kepada tujuan penelitian, yaitu dengan mewawancarai beberapa pihak yang terlibat pada proses penjadwalan

b. Observasi, pengumpulan data dengan cara melakukan pengamatan melalui kelayakan terhadap objek yang ingin diteliti dan dilakukan dalam situasi khusus.

\subsection{Studi Pustaka}


Metode yang digunakan untuk mendapatkan informasi adalah dengan mempelajari dari beberapa sumber yang berkaitan dengan judul penelitian sebagai referensi dan dijadikan sebagai bahan perbandingan, adapun referensi yang digunakan sebagai berikut :

1. Kajian Empiris

Penelitian tentang pewarnaan graf yang sama telah banyak dilakukan antara lain:

1) Perancangan Sistem Penjadualan Kuliah di Jurusan Teknik Elektro Ft.Untrirta Menggunakan Teknik Pewarnaan Graph Algoritma Backtracking Welch-Powell. Pada penelitian ini, menjelaskan bahwa penjadwalan kuliah menggunakan teori graph, data yang berhubungan dengan jadwal diubah dalam bentuk graph, kemudian untuk mengetahui banyaknya warna untuk solusi awal digunakan bilangan khromatik, untuk menyelesaikan masalah pewarnaan graph digunakan algoritma backtracking Welch-Powell [1].

2) Penerapan Pewarnaan Simpul Graf untuk Menentukan Jadwal Ujian Skripsi Pada STMIK Amik Riau Menggunakan Algoritma Welch-Powell . Pada penelitian ini, penjadwalan ujian skripsi menggunakan teknik pewarnaan simpul graf dengan menggunakan algoritma Welch-powell, hasil penelitian memperlihatkan bahwa algoritma ini dapat diterapkan dalam pembuatan jadwal skripsi dengan memberikan hasil penjadwalan yang lebih baik dari metode sebelumnya [2].

2. Pewarnaan Graf adalah sebuah metode pelebelan pada sebuah graf. Pelebelan tersebut merupakan pemberuan warna pada simpul, sisi ataupun wilayah (region). Dalam pewarnaan pada indeks kromatik atau angka kromatik sisi yang disimbolkan $x^{\prime}(\mathrm{G})$ yaitu angka terkecil yang diperlukan untuk pewarnaan sisi graf G [3].

Ada beberapa macam teknik pewarnaan dalam graf yaitu

1) Pewarnaan Simpul, merupakan cara mewarnai simpul-simpul suatu graf sedemikian hingga tidak ada dua simpul bertetangga yang berwarna sama dengan kata lain warna pada simpul boleh sembarang asalkan berbeda dengan simpul tetangganya

2) Pewarnaan Sisi, merupakan suatu proses mewarnai pada garis (edges) dengan warna-warna tertentu sehingga setiap titik (vertex) yang bertemu pada titik (vertex) yang sama mempunyai warna yang berbeda. Cara mewarnai sisi k dinamakan pewarnaan sisi $\mathrm{k}$.

3) Pewarnaan Wilayah, merupakan teknik mewarnai masing-masing wilayah graf sehingga tidak ada warna yang sama pada wilayah graf yang bersebelahan.

\section{ANALISA DAN PEMBAHASAN}

Pada tahapan ini proses yang dilakukan untuk pengembangan dan menganalisa adalah :

a. Analisis Data adalah mengenai data apa saja yang akan diproses, baik sebagai masukan maupun keluaran. Data yang di perlukan antara lain :

1) Data Dosen, data yang berisikan nama dosen yang mengajar pada STMIK Widya Cipta Dharma Samarinda.

2) Data Mata Kuliah, data mata kuliah berisi daftar mata kuliah yang ada pada STMIK Widya Cipta Dharma Samarinda. Daftar mata kuliah untuk prodi teknik informatika, prodi sistem informasi dan mata kuliah yang ada pada manajemen informatika.

3) Data Ruangan, data ruangan berisi daftar ruangan yang ada pada STMIK Widya Cipta Dharma Samarinda. Dimana untuk ruangan yang biasa digunakan untuk prodi teknik informatika adalah ada 5 ruangan yaitu ruang 2, 4/6, 12, 14 dan 15 . Untuk prodi sistem informasi ruangan yang biasa digunakan ada 5 ruangan yaitu ruang $1,3 / 5,11,16$ dan 17 . Sedangkan untuk prodi manajemen informatika ruangan yang biasa digunakan ada 4 ruangan yaitu ruang 7, 8, 9 dan 10 .

4) Data Kelas, data kelas berisi tentang daftar kelas yang ada pada prodi teknik informatika, sistem informasi dan manajemen informatika pada STMIK Widya Cipta Dharma Samarinda.

5) Data Waktu, data waktu berisi tentang waktu-waktu yang digunakan dalam proses mengajar yang dilakukan pada STMIK Widya Cipta Dharma Samarinda. Dimana untuk mata kuliah 2 sks kelas pagi dimulai pada jam 08.00-11.40, untuk mata kuliah 3 sks pada jam 13.00-15.30. Sedangkan untuk kelas malam, mata kuliah 3 sks ditempatkan pada hari senin dan selasa pada jam 19.00-20.15, sedangkan mata kuliah 2 sks dimulai dari jam 16.30-22.00 tiap harinya kecuali hari senin dan selasa hanya ada pada jam 16.30.

b. Analisis Sistem

Pada tahap ini bertujuan untuk memberikan gambaran umum kepada pemakai tentang sistem teknologi informasi yang baru dengan menggunakan alat bantu perancangannya adalah Flowchart. 


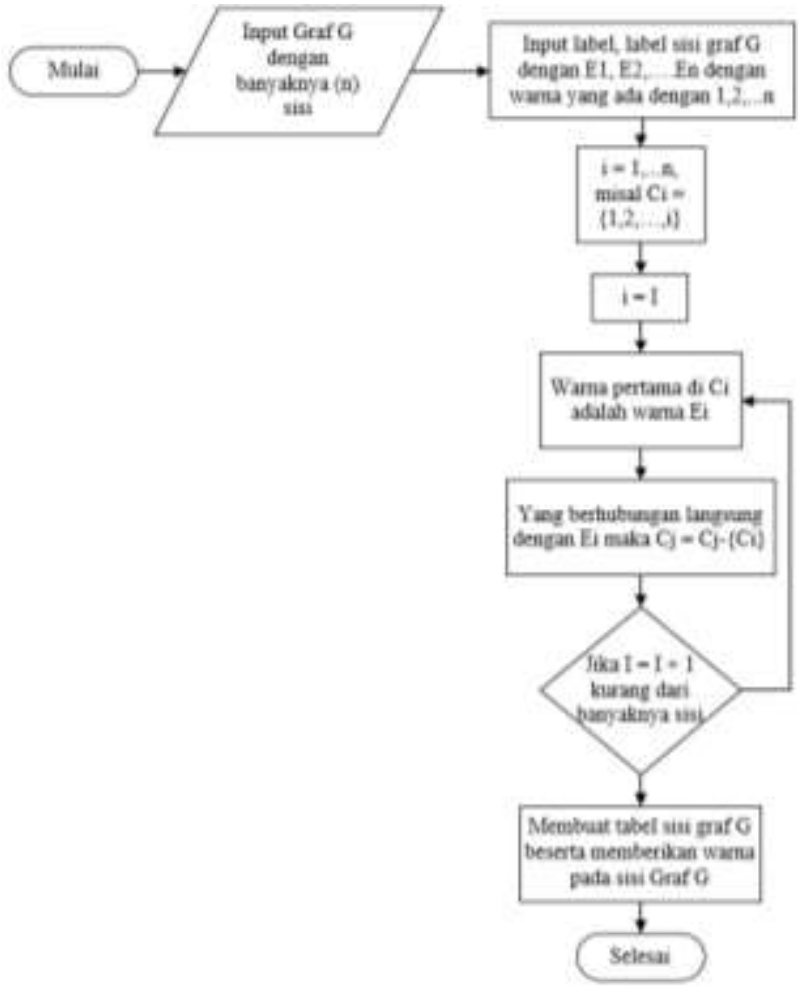

Gambar 1. Flowchat Algoritma Pewarnaan Barisan Sederhana Pada Sisi

Pada gambar 1 merupakan alur flowchart dari sistem penjadwalan pada STMIK Widya Cipta Dharma Samarinda menggunakan metode pewarnaan graf pada sisi. Dimulai dari menginputkan banyaknya sisi yang ada pada graf $\mathrm{G}$ dan dilanjutkan pada step-step sebagai berikut :

1. Step 1 : Memberikan label kepada setiap sisi yang ada pada graf $G$ dengan label $E_{1}, E_{2}, \ldots E_{n}$. Dan warna yang disediakan sama dengan banyaknya sisi yang ada pada graf $\mathrm{G}$.

2. Step 2 : i sama dengan banyaknya sisi yang ada pada graf $G$. Dan $C_{i}$ adalah daftar warna yang disediakan untuk memberikan warna pada graf $\mathrm{G}$.

3. Step 3 : i sama dengan I, I dimulai dari 1 atau sisi $1\left(E_{1}\right)$

4. Step 4 : Warna pertama yang disediakan pada step $2\left(\mathrm{C}_{\mathrm{i}}\right)$, maka warna tersebut adalah warna yang akan diberikan pada $\mathrm{E}_{\mathrm{i}}$

5. Step 5 : Yang berhubungan langsung dengan sisi yang sedang dieksekusi, maka sisi yang berhubungan tidak dapat menggunakan warna yang sama dengan sisi yang sedang dieksekusi. Dan $\mathrm{i}=\mathrm{I}+1$. Apabila hasil i lebih dari banyaknya sisi yang ada pada graf $\mathrm{G}$ maka lanjut pada step 6, jika kurang atau sama dengan sisi yang ada pada graf $\mathrm{G}$ maka kembali melakukan step 4.

6. Step 6 : Membuat tabel hasil pewarnaan sisi pada graf G.

\section{IMPLEMENTASI}

Setelah semua dianalisis, maka tahap selanjutnya adalah implementasi

\subsection{Proses Pewarnaan Graf}

Proses pewarnaan graf antara vertex kelas dan vertex mata kuliah pada kelas dan mata kuliah 2 sks di semester I pada prodi teknik informatika kelas pagi

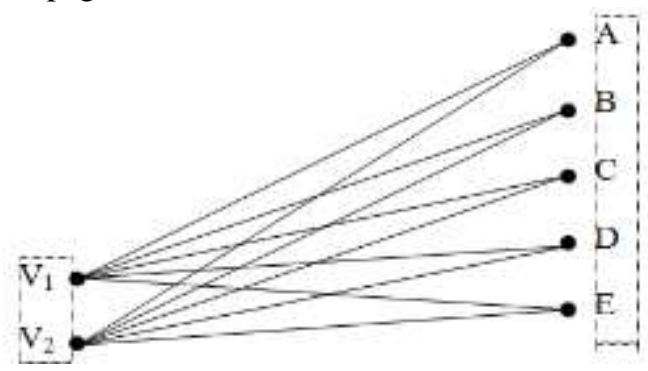

Gambar 2. Graf kelas yang ada di semester 1, mata kuliah 2 sks di semester 1, dan kelas pagi Amelia Yusnita | http://ejurnal.stmik-budidarma.ac.id/index.php/mib | Page 155 
Pada gambar 2 dijelaskan bahwa :

$\mathrm{V}_{1}=\mathrm{PA}$

$\mathrm{V}_{2}=\mathrm{PB}$

$\mathrm{A}=$ Agama Islam

$\mathrm{B}=$ Alpro Dasar

$\mathrm{C}=$ Bahasa Inggris I

$\mathrm{D}=$ Fisika

$\mathrm{E}=$ Bahasa Indonesia

1 = Biru, 2 = Merah, $3=$ Hijau, $4=$ Ungu, $5=$ Hitam, $6=$ Orange, $7=$ Hitam, $8=$ Biru Laut, $9=$ Coklat, $10=$ AbuAbu.

Diketahui:

$\mathrm{E}_{1}=\mathrm{V}_{1}-\mathrm{A}, \mathrm{E}_{2}=\mathrm{V}_{1}-\mathrm{B}, \mathrm{E}_{3}=\mathrm{V}_{1}-\mathrm{C}, \mathrm{E}_{4}=\mathrm{V}_{1}-\mathrm{D}, \mathrm{E}_{5}=\mathrm{V}_{1}-\mathrm{E}$,

$\mathrm{E}_{6}=\mathrm{V}_{2}-\mathrm{A}, \mathrm{E}_{7}=\mathrm{V}_{2}-\mathrm{B}, \mathrm{E}_{8}=\mathrm{V}_{2}-\mathrm{C}, \mathrm{E}_{9}=\mathrm{V}_{2}-\mathrm{D}, \mathrm{E}_{10}=\mathrm{V}_{2}-\mathrm{E}$

Langkah-langkah penyelesaian :

Step 1 : Label warna yang tersedia adalah $1,2,3,4,5,6,7,8,9,10$.

Step $2: C_{1}=\{1\}, C_{2}=\{1,2\}, C_{3}=\{1,2,3\}, C_{4}=\{1,2,3,4\}, C_{5}=\{1,2,3,4,5\}, C_{6}=\{1,2,3,4,5,6\}$

$\mathrm{C}_{7}=\{1,2,3,4,5,6,7\}, \mathrm{C}_{8}=\{1,2,3,4,5,6,7,8\}, \mathrm{C}_{9}=\{1,2,3,4,5,6,7,8,9\}$

Step $3: \mathrm{i}=1$

$\mathrm{C}_{10}=\{1,2,3,4,5,6,7,8,9,10\}$

Step 4 : 1 adalah warna pertama di $\mathrm{C}_{1}$. Jadi warna sisi $\mathrm{E}_{1}$ dengan warna 1

Step 5 : sisi yang berhubungan langsung dengan titik yang ada di $E_{1}$ adalah $E_{2}, E_{3}, E_{4}, E_{5}, E_{6}$.

$$
\begin{aligned}
& \mathrm{C}_{2}=\{1,2\}-\{1\}=\{2\} \\
& \mathrm{C}_{3}=\{1,2,3\}-\{1\}=\{2,3\} \\
& \mathrm{C}_{4}=\{1,2,3,4\}-\{1\}=\{2,3,4\} \\
& \mathrm{C}_{5}=\{1,2,3,4,5\}-\{1\}=\{2,3,4,5\} \\
& \mathrm{C}_{6}=\{1,2,3,4,5,6\}-\{1\}=\{2,3,4,5,6\} \\
& \mathrm{i}=1+1=2
\end{aligned}
$$

Step $4: \mathrm{E}_{2}=2$

Step 5 : sisi yang berhubungan langsung dengan titik yang ada di $\mathrm{E}_{2}$ adalah $\mathrm{E}_{3}, \mathrm{E}_{4}, \mathrm{E}_{5}, \mathrm{E}_{7}$.

$$
\begin{aligned}
& \mathrm{C}_{3}=\{2,3\}-\{2\}=\{3\} \\
& \mathrm{C}_{4}=\{2,3,4\}-\{2\}=\{3,4\} \\
& \mathrm{C}_{5}=\{2,3,4,5\}-\{2\}=\{3,4,5\} \\
& \mathrm{C}_{7}=\{1,2,3,4,5,6,7\}-\{2\}=\{1,3,4,5,6,7\} \\
& \mathrm{i}=2+1=3
\end{aligned}
$$

Step $4: \mathrm{E}_{3}=3$

Step 5 : sisi yang berhubungan langsung dengan titik yang ada di $E_{3}$ adalah $E_{4}, E_{5}, E_{8}$.

$$
\begin{aligned}
& \mathrm{C}_{4}=\{3,4\}-\{3\}=\{4\} \\
& \mathrm{C}_{5}=\{3,4,5\}-\{3\}=\{4,5\} \\
& \mathrm{C}_{8}=\{1,2,3,4,5,6,7,8\}-\{3\}=\{1,2,4,5,6,7,8\} \\
& \mathrm{i}=3+1=4
\end{aligned}
$$

Step $4: \mathrm{E}_{4}=4$

Step 5 : sisi yang berhubungan langsung dengan titik yang ada di $\mathrm{E}_{4}$ adalah $\mathrm{E}_{5}, \mathrm{E}_{9}$.

$$
\begin{aligned}
& \mathrm{C}_{5}=\{4,5\}-\{4\}=\{5\} \\
& \mathrm{C}_{9}=\{1,2,3,4,5,6,7,8,9\}-\{4\}=\{1,2,3,5,6,7,8,9\} \\
& \mathrm{i}=4+1=5
\end{aligned}
$$

Step $4: \mathrm{E}_{5}=5$

Step 5 : sisi yang berhubungan langsung dengan titik yang ada di $\mathrm{E}_{5}$ adalah $\mathrm{E}_{10}$.

$$
\begin{aligned}
& \mathrm{C}_{10}=\{1,2,3,4,5,6,7,8,9,10\}-\{5\}=\{1,2,3,4,6,7,8,9,10\} \\
& \mathrm{i}=5+1=6
\end{aligned}
$$

Step $4: \mathrm{E}_{6}=2$

Step 5 : sisi yang berhubungan langsung dengan titik yang ada di $\mathrm{E}_{6}$ adalah $\mathrm{E}_{7}, \mathrm{E}_{8}, \mathrm{E}_{9}, \mathrm{E}_{10}$.

$$
\begin{aligned}
& \mathrm{C}_{7}=\{1,3,4,5,6,7\}-\{2\}=\{1,3,4,5,6,7\} \\
& \mathrm{C}_{8}=\{1,2,4,5,6,7,8\}-\{2\}=\{1,4,5,6,7,8\} \\
& \mathrm{C}_{9}=\{1,2,3,5,6,7,8,9\}-\{2\}=\{1,3,5,6,7,8,9\} \\
& \mathrm{C}_{10}=\{1,2,3,4,6,7,8,9,10\}-\{2\}=\{1,3,4,6,7,8,9,10\} \\
& \mathrm{i}=6+1=7
\end{aligned}
$$

Step $4: \mathrm{E}_{7}=1$

Step 5 : sisi yang berhubungan langsung dengan titik yang ada di $\mathrm{E}_{7}$ adalah $\mathrm{E}_{8}, \mathrm{E}_{9}, \mathrm{E}_{10}$. 


$$
\begin{aligned}
& \mathrm{C}_{8}=\{1,4,5,6,7,8\}-\{1\}=\{4,5,6,7,8\} \\
& \mathrm{C}_{9}=\{1,3,5,6,7,8,9\}-\{1\}=\{3,5,6,7,8,9\} \\
& \mathrm{C}_{10}=\{1,3,4,6,7,8,9,10\}-\{1\}=\{3,4,6,7,8,9,10\} \\
& \mathrm{i}=7+1=8
\end{aligned}
$$

Step $4: \mathrm{E}_{8}=4$

Step 5 : sisi yang berhubungan langsung dengan titik yang ada di $\mathrm{E}_{8}$ adalah $\mathrm{E}_{9}, \mathrm{E}_{10}$.

$$
\begin{aligned}
& \mathrm{C}_{9}=\{3,5,6,7,8,9\}-\{4\}=\{3,5,6,7,8,9\} \\
& \mathrm{C}_{10}=\{3,4,6,7,8,9,10\}-\{4\}=\{3,6,7,8,9,10\} \\
& \mathrm{i}=8+1=9
\end{aligned}
$$

Step $4: \mathrm{E}_{9}=3$

Step 5 : sisi yang berhubungan langsung dengan titik yang ada di $\mathrm{E}_{9}$ adalah $\mathrm{E}_{10}$.

$$
\begin{aligned}
& C_{10}=\{3,6,7,8,9,10\}-\{3\}=\{6,7,8,9,10\} \\
& i=9+1=10
\end{aligned}
$$

Step $4: \mathrm{E}_{10}=6$

Step 5 : sisi yang berhubungan langsung dengan titik yang ada di $\mathrm{E}_{10}$ semua sudah di eksekusi jadi lanjut ke step 6.

Step 6 : Table titik titik $\mathrm{G}$ dan warnanya

Tabel 1. Hasil Pewarnaan

\begin{tabular}{lllllllllll}
\hline $\mathrm{E}(\mathrm{G})$ & $\mathrm{E}_{1}$ & $\mathrm{E}_{2}$ & $\mathrm{E}_{3}$ & $\mathrm{E}_{4}$ & $\mathrm{E}_{5}$ & $\mathrm{E}_{6}$ & $\mathrm{E}_{7}$ & $\mathrm{E}_{8}$ & $\mathrm{E}_{9}$ & $\mathrm{E}_{10}$ \\
\hline Warna $\mathrm{E}_{\mathrm{i}}$ & 1 & 2 & 3 & 4 & 5 & 2 & 1 & 4 & 3 & 6 \\
\hline
\end{tabular}

Hasil dari pewarnaan graf sebagai brikut :

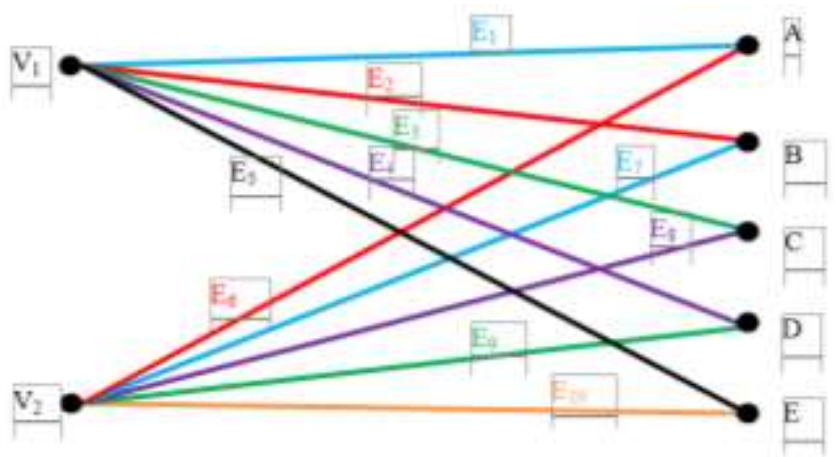

Gambar 3. Hasil Pewarnaan

Pada gambar 2, adalah hasil hari pewarnaan antara vertex kelas dan mata kuliah 2 sks yang ada pada semester I prodi teknik informatika kelas pagi. Jadi, untuk slot waktu yang digunakan adalah 6 waktu. Untuk waktu pada kelas pagi yaitu dari jam 08.00-15.30. Untuk warna yang sama bisa menggunakan waktu yang sama tetapi ruangan yang berbeda.

1. Warna Biru untuk (PA,Agama Islam), (PB,Alpro Dasar)

2. Warna Merah untuk (PA,Alpro Dasar), (PB,Agama Islam)

3. Warna Hijau untuk (PA, Bahasa Inggris I), (PB,Fisika)

4. Warna Ungu untuk (PA,Fisika), (PB,Bahasa Inggris I)

5. Warna Hitam untuk (PA, Bahasa Indonesia)

6. Warna Orange untuk (PB, Bahasa Indonesia)

Adapun hasil dari pewarnaan graf untuk mata kuliah 2 sks pada semester 1 kelas pagi prodi teknik informatika yaitu ada 6 warna yang di dapatkan pada gambar 3,6 warna yang didapatkan pada graf G pada penjadwalan ini digunakan untuk waktu pada penjadwalan mata kuliah. Jadi, 6 warna adalah 6 waktu yang dapat digunakan pada mata kuliah 2 sks semester 1 kelas pagi teknik informatika. Untuk penjadwalan mata kuliah ini, pada warna yang sama maka dapat menggunakan waktu yang sama tetapi untuk ruangan yang berbeda. Hasil penjadwalan dapat dilihat pada tabel 2 sebagai berikut :

Tabel 2. Hasil Jadwal

\begin{tabular}{llllll}
\hline Warna & Jam & Ruangan & Hari & Matkul & Kelas \\
\hline Biru & $08.00-09.40$ & 7 & Senin & Agama Islam & PA \\
Biru & $08.00-09.40$ & 9 & Senin & Alpro Dasar & PB \\
Merah & $08.00-09.40$ & 9 & Selasa & Alpro Dasar & PA \\
Merah & $08.00-09.40$ & 12 & Selasa & Agama Islam & PB \\
Hijau & $08.00-09.40$ & 1 & Rabu & Bahasa Inggris I & PA \\
Hijau & $08.00-09.40$ & 12 & Rabu & Fisika & PB \\
\hline
\end{tabular}




\begin{tabular}{llllll}
\hline Warna & Jam & Ruangan & Hari & Matkul & Kelas \\
\hline Ungu & $10.00-11.40$ & $4 / 6$ & Senin & Fisika & PA \\
Ungu & $10.00-11.40$ & 10 & Senin & Bahasa Inggris I & PB \\
Hitam & $10.00-11.40$ & 12 & Selasa & Bahasa Indonesia & PA \\
Orange & $10.00-11.40$ & 10 & Rabu & Bahasa Indonesia & PB \\
\hline
\end{tabular}

\subsection{Tampilan Interface}

Pada gambar 4, merupakan proses penjadwalan matakuliah secara otomatis, data yang harus diinputkan terlebih dahulu adalah data dosen pengampu matakuliah, data kelas, data ruang dan data waktu, setelah data yang diperlukan sudah tersedia maka klik tombol Proses Jadwal, dari proses jadwal tersebut akan tampil jadwal matakuliah yang sesuai dengan data dosen yang telah diinputkan sebelumnya.

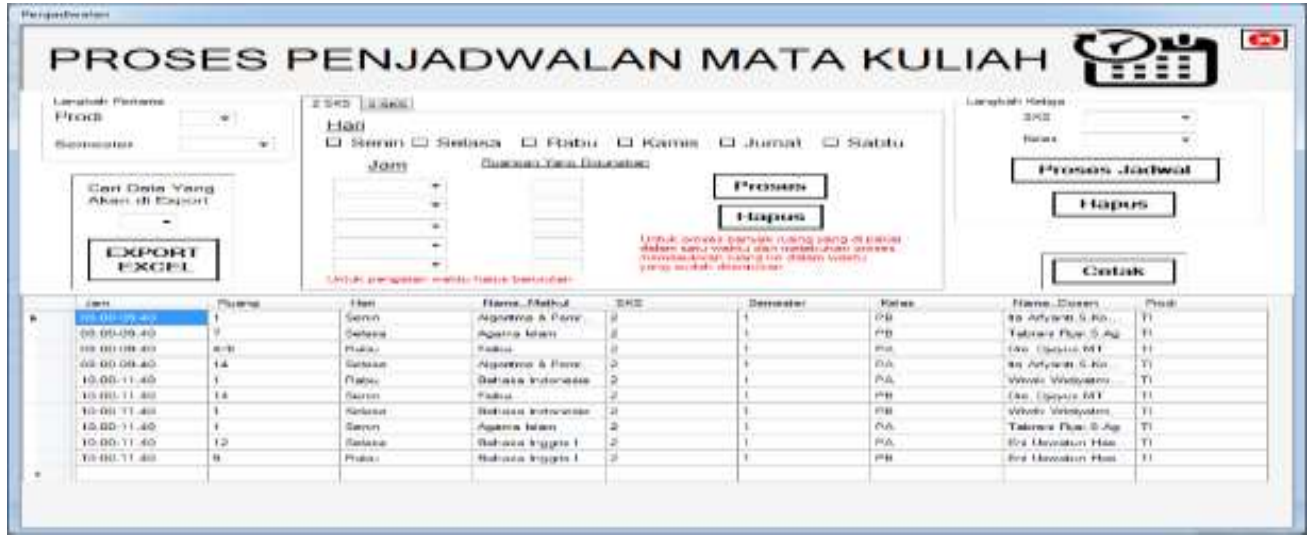

Gambar 4. Proses Penjadwalan Mata kuliah

\subsection{Pengujian}

Pengujian menggunakan Black Box Testing. Metode ini dilakukan dengan cara menjalankan atau mengeksekusi program yang dihasilkan. Kemudian diamati apakah hasil dari program tersebut sesuai dengan hasil yang diinginkan. Pengujian ini akan menguji secara detail dari tombol tambah dan tombol proses, hasil yang diharapkan adalah keberhasilan. Jika masih terdapat kesalahan atau terdapat hasil yang tidak sesuai dengan yang diinginkan, maka kesalahan ataupun ketidaksesuaian tersebut dicatat untuk selanjutnya dicek satu per satu dan diperbaiki.

\begin{tabular}{llll} 
& & Table 3. Pengujian Black Box & \\
\hline No & Uraian & Hasil Yang Diharapkan & Hasil Pengujian \\
\hline 1 & Tombol Tambah & $\begin{array}{l}\text { Pada saat ingin tambah data maka } \\
\text { klik tombol tambah, maka akan }\end{array}$ & $\square$ Tidak berhasil \\
& & $\begin{array}{l}\text { tampil form input guna untuk } \\
\text { memasukkan data baru. }\end{array}$ & \\
& & Ketika pengguna klik tombol & $\square$ Berhasil \\
& proses, sistem akan langsung & $\square$ Tidak berhasil \\
& Tombol Proses & &
\end{tabular}

\section{KESIMPULAN}

Disimpulkan bahwa dengan menerapkan metode pewarnaan graf untuk penjadwalan matakuliah dapat mempermudah program studi dalam menyusun jadwal perkuliahan tiap semesternya, sehingga menghindari terjadinya tumpang tindih antara mata kuliah, dosen, ruangan dan waktu yang bersamaan. Hasil akhirnya sebelum digunakan, dilakukan pengujian black box, dengan menguji apakah fungsi-fungsi dalam aplikasi tersebut berjalan dengan baik. Diharapkan kedepannya aplikasi dapat dikembangkan dengan melihat kapasitas ruangan yang tersedia dan tidak berfokus pada satu waktu.

\section{REFERENCES}

[1] R. Munarto and E. Permata, "Perancangan Sistem Penjadualan Kuliah di Jurusan Teknik Elektro Ft.Untrirta Menggunakan Teknik Pewarnaan Graph Algoritma Backtracking Welch-Powell,” Semin. Nas. Inov. Teknol. UN PGRI Kediri, pp. 277-282, 2017.

[2] K. Harianto and T. S. E. Fatdha, "Penerapan Pewarnaan Simpul Graf untuk Menentukan Jadwal Ujian Skripsi pada STMIK AMIK Riau Menggunakan Algoritma Welch-Powell," Sains dan Teknol. Inf., vol. 1, no. 2, pp. 48-54, 2015.

[3] N. Yannuansa and R. Ramadhani, "Penggunaan Graf Dalam Penjadwalan Perkuliahan Teknik Elektro Universitas Hasyim Asy'Ari," $J$. Reaktom, vol. 1, no. 2, pp. 33-35, 2018. 